\title{
Case report: vertical dengue infection
}

\author{
Samara L. C. Maroun, ${ }^{1}$ Roberta C. C. Marliere, ${ }^{2}$ Rovena C. Barcellus, ${ }^{2}$

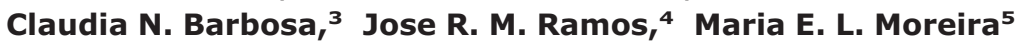

\begin{abstract}
Objectives: To report a case of vertical dengue infection in a newborn from Rio de Janeiro, Brazil, and to review the literature concerning this problem.

Description: We report a case of vertical dengue infection. Female neonate, birth weight 3,940 g, term, was admitted to a neonatal intensive care unit on the fifth day of life with fever and erythematous rash. Her mother had had dengue fever 3 days before delivery. Her platelet count was 38,000, dropping to 15,000. She did not have any hemorrhagic episodes, including cerebral hemorrhages. Anti-dengue antibodies (IgM) were positive in the mother and infant. Dengue type 2 was detected in the infant using polymerase chain reaction.
\end{abstract}

Comments: This report emphasizes that pediatricians should be aware of the possibility of vertical dengue infection so that early management can be instituted.

J Pediatr (Rio J). 2008;84(6):556-559: Pregnancy, dengue, neonate.

\section{Introduction}

Dengue is an acute febrile disease caused by a virus of the flavivirus genus that belongs to the family Flaviviridae. Currently, it is the most important arboviral disease (disease transmitted by arthropods) affecting humans. Dengue is a serious problem for public health worldwide, mainly in tropical countries where environmental conditions favor the development and the dissemination of Aedes aegypti, the main dengue vector. Four serum types are known: $1,2,3$ and $4 .{ }^{1}$ Although mosquito bite is the main mode of dengue transmission, there are no reports of vertical dengue infection in the current literature, which, together with the increase in the number of cases in the population, mainly regarding non-classical dengue, is a reason for additional concern for health professionals. ${ }^{1-3}$

Therefore, the objective of this case report is to raise awareness to the possibility of mother-child transmission of dengue, which initially affects the newborn presenting a clinical picture similar to neonatal sepsis, thus leading to the possibility of not being diagnosed. ${ }^{1}$

\section{Case report}

Female newborn (NB), birth weight 3,940 g, term, was admitted to the neonatal intensive care unit (NICU) with erythematous rash, hypoactivity and fever on the fifth day of life. The patient was transferred from the mother-baby unit. After being admitted to the NICU, the newborn was screened for bacterial infection, and antibiotic therapy was initiated with ampicillin and amikacin. The blood sample collected 24 hours after the antibiotic therapy was implemented showed severe thrombocytopenia (38,000 platelets). The mother had fever and symptoms compatible with virosis 3 days before the delivery. However, since she did not believe these symptoms were

1. Médica residente, Instituto Fernandes Figueira, Fundação Oswaldo Cruz (Fiocruz), Rio de Janeiro, RJ, Brazil.

2. Médica residente, Instituto Fernandes Figueira, Fiocruz, Rio de Janeiro, RJ, Brazil.

3. Médica neonatologista. Responsável, alojamento conjunto, Instituto Fernandes Figueira, Fiocruz, Rio de Janeiro, RJ, Brazil.

4. Chefe, Departamento de Neonatologia, Instituto Fernandes Figueira, Fiocruz, Rio de Janeiro, RJ, Brazil.

5. Médica neonatologista. Docente permanente, Pós-Graduação em Saúde da Criança e da Mulher, Instituto Fernandes Figueira, Fiocruz, Rio de Janeiro, RJ, Brazil.

No conflicts of interest declared concerning the publication of this article.

Suggested citation: Maroun SL, Marliere RC, Barcellus RC, Barbosa CN, Ramos JR, Moreira ME. Case report: vertical dengue infection. J Pediatr (Rio J). 2008;84(6):556-559.

Manuscript received Apr 07 2008, accepted for publication Jun 252008.

doi:10.2223/JPED.1826 
related to dengue, the problems were not reported at the hospital or health service unit. Anti-dengue antibodies (IgM) were collected from the mother and infant to be analyzed using the ELISA (enzyme-linked immunosorbent assay) method. The results were positive for both of them. Type 2 dengue was detected in the infant using the polymerase chain reaction (PCR). The number of platelets dropped to 15,000 , and the hepatic transaminases elevated (GOT 1987, GPT 863, ALP 427). The NB was adequately hydrated, received a unit of platelets and was kept under antibiotic therapy for 7 days up to the confirmation of the dengue diagnosis using serology. The infant was discharged from hospital 20 days after delivery in good clinical status. She was being breastfed at the time, and had normal platelet count and normal transaminases. The hospital is located in the South area of the city of Rio de Janeiro, which means it is not in the geographical zone at highest risk for dengue infection, and there was no other case at the time involving in-patients or hospital personnel. The control of dengue vectors performed by Fundação Oswaldo Cruz (Fiocruz) did not find Aedes aegypti focuses nearby the hospital, which reduces the possibility of postnatal infection.

\section{Discussion}

To date, few cases of vertical dengue infection have been published in the literature. ${ }^{1-6}$ The largest series of cases with neonatal consequences to be reported includes 10 cases in Asia (Thailand and Malaysia), two cases in Europe (France) and five cases in Latin America (Tahiti). ${ }^{1}$ Another series of cases involving pregnant women was reported in Sri Lanka, including 26 cases of dengue occurring at different phases of pregnancy with severe consequences for seven pregnant women and a report that eight women were initially treated for other diseases. The fetal consequences of the cases from Sri Lanka were rare (one miscarriage and a preterm delivery), but none of the pregnant women had dengue symptoms on the days just before the delivery. ${ }^{2} \mathrm{~A}$ review including 38 severe cases of dengue during pregnancy registered in the French Guiana evidenced an increase in preterm deliveries and fetal death involving in-patients. And in a series of 59 cases of dengue during pregnancy registered in the 1981 epidemic caused by type 2 virus in Cuba, there are reports of four cases of NBs with positive IgM. ${ }^{3,4}$ In our case, the mother did not have severe symptoms of dengue, although she had positive IgM, which suggested recent infection. The severity of the pregnant woman's clinical picture varies among the different series of cases presented here, but the literature includes reports of nondifferentiable cases of HELLP syndrome (hemolysis, elevated liver enzymes and low platelet count). ${ }^{1,7}$

The immunopathogenesis of vertical dengue infection has not been well established yet; however, the newborns' clinical characteristics described in the previous reports were also found in our clinical case. In addition, severe hemorrhagic complications in NBs are not commonly found, although there are reports of severe thrombocytopenia (most of them $<30,000)^{1}$

Regarding the fetus, authors have reported an increase in the incidence of neural tube malformation in NBs whose mothers had dengue in the first quarter of pregnancy during a dengue epidemic in India. ${ }^{5}$ There are also reports of preterm deliveries and low birth weight. ${ }^{1,3}$ Some authors have reported that severe dengue affects the NB only when the mother's symptoms occur close to term or delivery time, and the mother has no time to produce protective antibodies. ${ }^{1,2,7}$

In our case, the hypothesis of vertical infection as opposed to the postnatal infection was based on the following aspects: (1) confirmed maternal infection close to delivery time; (2) 5-day incubation period; (3) absence of Aedes aegypti focuses nearby the hospital and absence of other cases of dengue.

We compared our case to the series of cases involving NBs and we found that the incubation period, the clinical manifestation and the laboratory tests were similar. The time interval between the beginning of fever in the pregnant woman and NB in the cases mentioned above ranged between 1 to 13 days (mean time $=7$ days), which is similar to our case..$^{1,7}$

Therefore, besides being a rare manifestation, we believe that vertical dengue infection is underdiagnosed and underreported, being excluded from the diagnosis of newborns presenting the clinical picture previously described, mainly in case of suspected maternal history of dengue. Moreover, due to the increase in the number of new cases of dengue, mainly severe cases, pregnant women have become more susceptible to this infection, what may lead to lethal consequences not only for the mother but also for the infant. The recent infection prevalence rate in pregnant women during an epidemic in Malaysia reached $2.5 \%$, and the rate of vertical dengue infection was $1.6 \% .^{7}$ According to sources from the Brazilian Institute of Geography and Statistics (IBGE), the population at reproductive age in the city of Rio de Janeiro (10-49 years) includes $1,997,134$ women, and the number of annual births is 80,000 deliveries/year. Taking into consideration the current number of cases and the period of time the disease takes to develop in NBs, usually between 5 and 13 days of life, that is, after hospital discharge, there might be cases of vertical infection that are not registered or diagnosed. ${ }^{8}$

Pregnant women and NBs' symptoms vary among the case reports published in the literature; however, in general, the most common symptoms include fever and thrombocytopenia. In our case, the mother reported symptoms similar to those of virosis: lethargy and fever (Table 1).

Therefore, the most adequate management when there is diagnostic suspicion of dengue during pregnancy is conservative management, avoiding anticipating the delivery. When there is possibility of imminent delivery, the NB must be carefully followed-up regarding his/her clinical evolution up to the second week of life. ${ }^{1,3}$ Follow-up throughout the first year of 
Table 1 - Case reports of dengue in pregnant women and newborns in the last 5 years with description of patients' symptoms

\begin{tabular}{|c|c|c|c|c|}
\hline References & Country & Number of cases & $\begin{array}{c}\text { Pregnant women's } \\
\text { symptoms }\end{array}$ & $\begin{array}{l}\text { Newborns' } \\
\text { symptoms }\end{array}$ \\
\hline Phongsamart et al. ${ }^{9}$ & Thailand & 3 & $\begin{array}{c}\text { Erythematous rash and } \\
\text { thrombocytopenia }\end{array}$ & $\begin{array}{c}\text { Fever, petechiae, and } \\
\text { hepatomegaly }\end{array}$ \\
\hline Sirinavin et al. ${ }^{1}$ & Thailand & 2 & $\begin{array}{l}\text { Thrombocytopenia and } \\
\text { elevated liver enzymes }\end{array}$ & $\begin{array}{c}\text { Fever, } \\
\text { thrombocytopenia, } \\
\text { elevated liver enzymes, } \\
\text { bleeding, and rash }\end{array}$ \\
\hline Petdachai et al. ${ }^{6}$ & Thailand & 1 & $\begin{array}{c}\text { Fever and } \\
\text { thrombocytopenia }\end{array}$ & $\begin{array}{c}\text { Thrombocytopenia, } \\
\text { leukopenia, petechiae, } \\
\text { and hepatomegaly }\end{array}$ \\
\hline Janjindamai \& Pruekprasert ${ }^{10}$ & Thailand & 1 & Fever & $\begin{array}{l}\text { Thrombocytopenia and } \\
\text { elevated liver enzymes }\end{array}$ \\
\hline Choudhry et al. ${ }^{11}$ & India & 4 & No information & $\begin{array}{l}\text { Fever, lethargy, shock, } \\
\text { and thrombocytopenia }\end{array}$ \\
\hline Witayathawornwong $^{12}$ & Thailand & 1 & $\begin{array}{c}\text { Thrombocytopenia and } \\
\text { pleural effusion }\end{array}$ & $\begin{array}{c}\text { Fever, } \\
\text { thrombocytopenia, and } \\
\text { pleural effusion }\end{array}$ \\
\hline Restrepo et al. ${ }^{13}$ & Colombia & 22 & No report & $\begin{array}{c}\text { Preterm delivery, fetal } \\
\text { malformations, and low } \\
\text { birth weight }\end{array}$ \\
\hline Fatimil et al. ${ }^{14}$ & Bangladesh & 1 & $\begin{array}{c}\text { Bleeding and pleural } \\
\text { effusion }\end{array}$ & $\begin{array}{l}\text { Fever and } \\
\text { thrombocytopenia }\end{array}$ \\
\hline Chotigeal et al. ${ }^{15}$ & Thailand & 2 & $\begin{array}{l}\text { Postpartum } \\
\text { hemorrhage }\end{array}$ & $\begin{array}{c}\text { Thrombocytopenia and } \\
\text { pleural effusion }\end{array}$ \\
\hline
\end{tabular}

life of three NBs who were vertically infected with dengue did not evidence long-term sequelae. ${ }^{9}$

\section{Acknowledgements}

We would to thank Instituto de Pesquisa Evandro Chagas for carrying out the tests.

\section{References}

1. Sirinavin $S$, Nuntnarumit $P$, Supapannachart $S$, Boonkasidecha $S$, Techasaensiri $C$, Yoksarn S. Vertical dengue infection: case reports and review. Pediatr Infect Dis J. 2004;23: 1042-7.

2. Waduge R, Malavige GN, Pradeepan M, Wijeyaratne CN, Fernando S, Seneviratne SL. Dengue infections during pregnancy: a case series from Sri Lanka and review of the literature. J Clin Virol. 2006;37:27-33.

3. Carles G, Talarmin A, Peneau C, Bertsch M. Dengue fever and pregnancy. A study of 38 cases in French Guiana. J Gynecol Obstet Biol Reprod (Paris). 2000;29:758-62.
4. Fernández R, Rodríguez T, Borbonet F, Vázquez S, Guzmán MG, Kouri G. Study of the relationship dengue-pregnancy in a group of Cuban-mothers. Rev Cubana Med Trop. 1994;46:76-8.

5. Sharma JB, Gulati N. Potential relationship between dengue fever and neural tube defects in a northern district of India. Int J Gynaecol Obstet. 1992;39:291-5.

6. Petdachai W, Sila'on J, Nimmannitya S, Nisalak A. Neonatal dengue infection: report of dengue fever in a 1-day-old infant. Southeast Asian J Trop Med Public Health. 2004;35:403-7.

7. Tan PC, Rajasingam G, Devi S, Omar SZ. Dengue infection in pregnancy: prevalence, vertical transmission, and pregnancy outcome. Obstet Gynecol. 2008;111:1111-7.

8. Instituto Brasileiro de Geografia e Estatística (IBGE). Síntese de indicadores sociais - 2006. http://www.ibge.gov.br. Access: 31/ 03/2008.

9. Phongsamart W, Yoksan S, Vanaprapa N, Chokephaibulkit K. Dengue virus infection in late pregnancy and transmission to the infants. Pediatr Infect Dis J. 2008;27:500-4.

10. Janjindamai W, Pruekprasert P. Perinatal dengue infection: a case report and review of literature. Southeast Asian J Trop Med Public Health. 2003;34:793-6. 
11. Choudhry SP, Gupta RK, Kishan J. Dengue shock syndrome in newborn: a case series. Indian Pediatr. 2004;41:397-9.

12. Witayathawornwong P. Parturient and perinatal dengue hemorrhagic fever. Southeast Asian J Trop Med Public Health. 2003;34:797-9.

13. Restrepo BN, Isaza DM, Salazar CL, Ramírez JL, Upegui GE, Ospina $M$, et al. Prenatal and postnatal effects of dengue infection during pregnancy. Biomedica. 2004;24:334-5.

14. Fatimil LE, Mollah AH, Ahmed S, Rahman M. Vertical transmission of dengue: first case report from Bangladesh. Southeast Asian J Trop Med Public Health. 2003;34:800-3.
15. Chotigeat U, Kalayanarooj S, Nisalak A. Vertical transmission of dengue infection in Thai infants: two case reports. J Med Assoc Thai. 2003; 86:S628-32.

Correspondence:

Maria Elisabeth Lopes Moreira

Instituto Fernandes Figueira

Avenida Rui Barbosa, 716

Departamento de Neonatologia

CEP 22250-020 - Rio de Janeiro, RJ - Brazil

Tel.: +55 (21) 2554.1819

E-mail: bebeth@iff.fiocruz.br 